\title{
Double Negatives Do Not Make a Positive Editorial Experience
}

\author{
Mark B. Mycyk
}

Published online: 7 July 2011

(C) American College of Medical Toxicology 2011

Keywords Grammar Double negative $\cdot$ Scientific writing

Although double negatives are often heard in Shakespeare's plays or during dramatic case presentations on morning rounds, double negatives in the same sentence are not needed in scientific writing. English grammar is unlike math: two negatives do not make a positive. The best scientific writing is clear, direct, and simple. Do not use two or more negatives in the same sentence or clause, because the two negatives do not cancel each other out but only add confusion to the text.

"Do not use no gastric lavage for patients with non-toxic ingestions" is an obvious violation of the double negative rule, but other examples can be more subtle.

\section{Example 1}

Incorrect Red skin is not uncommon in patients treated with hydroxocobalamin.

Correct Red skin is common in patients treated with hydroxocobalamin.

\section{Example 2}

Incorrect Nausea and vomiting were not infrequently reported during phase II trials of that drug.

Correct Nausea and vomiting were frequently reported during phase II trials of that drug.

\section{Example 3}

Incorrect It is not unusual for writers of case reports to speculate too readily.

Correct Writers of case reports tend to speculate too readily.

Eliminating double negatives will enhance the clarity of your message to readers and make your writing more active. Remember, scientific writing is not creative writing. Shakespeare was a master of using the double negative for dramatic emphasis almost 400 years ago, but in today's scientific writing, double negatives do not make a positive editorial experience.

Conflicts of Interest None.

M. B. Mycyk ( $\varangle)$

Cook County Hospital, Toxikon Consortium,

1900 West Polk Street,

Chicago, IL 60612, USA

e-mail: mmycyk@ccbh.org 